\title{
Irrigation water resource management: 'IW-QC2' software tool
}

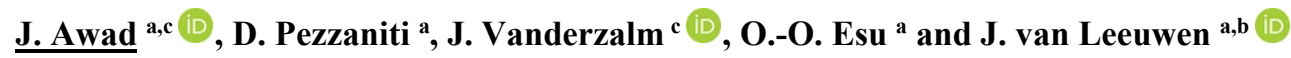 \\ ${ }^{a}$ School of Natural and Built Environments, ${ }^{b}$ Future Industries Institute, Adelaide, University of South \\ Australia, Australia, ${ }^{c}$ CSIRO Land \& Water, Adelaide, South Australia \\ Email: John.awad@mymail.unisa.edu.au
}

\begin{abstract}
It is well recognized that current practices and sustainable expansion of horticulture in the Northern Adelaide Corridor region (including the Northern Adelaide Plains, NAP), South Australia are strongly influenced by the availability of reliable water resources of suitable quality for the range of crops grown in horticulture practice. Further considerations are the type and condition of soils for soil-based enterprises and the range of climatic conditions expected in the region, including extreme events, of short and long-term duration.
\end{abstract}

Irrigation practices within covered (greenhouse) horticulture industries vary depending on a range of factors including crop type grown, crop evapotranspiration (ETc) rate, being soil-based or hydroponic, ambient temperatures and water supply quality, e.g. salinity. From a landholder survey conducted in 2018 to determine water management in soil-based horticulture practices of the NAP, it was found that ambient temperaturebased irrigation schedules are applied for soil-based open horticultural practices and additional irrigation is applied to leach of salts from the soil profile. For the hydroponics industry of the NAP, decentralized reverse osmosis treatment is used to desalinate groundwater and brackish recycled water.

In this paper, we describe a tool design to enable rapid determination of the quantity and quality of irrigation water produced through blending of different water sources. These sources include harvested stormwater, recycled water, local surface streamflow and ground waters. This tool is currently for soil-based greenhouse crops (i.e. tomato, cucumber, capsicum and eggplant) commonly grown in the NAP region but can be readily modified to include other covered crops. The modelled surface water supply (volumes and quality) can be calculated from historical climate data or future climate predictions. Model options include prediction of water harvested from greenhouse roofs (with user selected climate models) used when initially available (during the wet season) or stored and used to blend with other water sources to achieve fit-for purpose water qualities specific for crop type and growth stages.

To model these scenarios, a software tool (in Microsoft Excel) termed 'Irrigation water quality and quantity for covered crops' (or 'IW-QC2') was developed. This is for application by water resource managers and the horticulture industry to facilitate decision-making on water resource selection, water storage capacities and quality of blended supply water, with user selected climate model. IW-QC2 output includes determination of the amount and quality of irrigation blended waters for soil-based crops and when desalination (reverse osmosis, RO) is required, based on the trigger values for TDS and chloride concentrations for irrigation water for specific crops.

Keywords: Greenhouse, irrigation, water resources, climate prediction 


\section{INTRODUCTION}

Horticulture and agriculture are important industries of the Northern Adelaide Corridor region of South Australia. Expansion of agribusiness in this region is of state and national importance for social and economic growth, demonstrated by South Australian and Federal government funding of the Northern Adelaide Irrigation Scheme, NAIS (PIRSA, 2017). This scheme is designed to expand the existing capacity of recycled water (current capacity of 12 GL via the Virginia Pipeline Scheme) sourced from the Bolivar Wastewater Treatment Plant for irrigation of horticulture practices, north of the Gawler River, South Australia. This expansion would consist of an additional $20 \mathrm{GL}$ of recycled water delivered to the Northern Adelaide Corridor. The horticulture industry of South Australia is diverse and includes low to high technology enterprises, covered (greenhousehydroponics and soil based) and open cropping for a wide range of crop types. The sustainability and expansion of diverse horticultural (and agricultural) enterprises in the region is highly influenced by the reliability of water resources in terms of both quantity and quality. Despite the expansion of recycled water to the region, the supply of adequate water of suitable quality for specific horticulture practices in the region remains challenging. The availability of recycled water is constrained by the range of the distribution network and horticulture development that is dependent on this water resource is restricted to those supply areas.

Although recycled water from domestic wastewaters may have elevated salinity (mean $>1,000 \mathrm{mg} / \mathrm{L}$ ), it may also contain significant amounts of nutrients (nitrogen and phosphorous), which can contribute to a crop's nutrient requirements, thereby saving on fertilizer costs (Kelly et al. 2001), for both covered and open soilbased horticulture. Some studies have shown that using recycled water for irrigation can alter the microbiological and physicochemical properties of soils including $\mathrm{pH}$, organic matter content, salinity, contaminants and soil structure (Steven et al., 2003), all of which may adversely affect crop productivity (Jaramillo \& Restrepo 2017) and soil. For the hydroponics industry, recycled water from domestic wastewater needs to be desalinated, as does groundwaters of unsuitable salinity. The application of reverse osmosis (RO) treatment is viable economically for medium to large enterprises producing high-value crops. The use of desalinated water in horticulture with controlled addition of nutrients and micronutrients has been shown to increase crop productivity and quality (Resh, 2002).

For soil-based horticulture, the industry relies on a range of water sources for irrigation. Additional water supply resources available in the region include groundwater, urban stormwater, runoff from greenhouse roofs and surface water from local rivers. Groundwater supply in the NAP Prescribed Wells Area (PWA) is through licensing of approved extractions, and over extraction incurs high penalty costs. Elsewhere, including the study area, groundwater can be of poor quality e.g. of high salinity. Local river water is variable in both quantity and quality with comparable or higher salinity than recycled water. Rainwater harvesting from greenhouse roofs and other impervious surfaces is a potential source of low salinity water that can be used directly as captured or used for blending to achieve a salinity level that is within the tolerance range for irrigating crops. The variability in water supplies and demands, and diversity in water qualities adds complexity to irrigation management (Reca et al., 2018).

In this paper we describe a newly developed software tool 'Irrigation Water Quality and Quantity for Covered Crops' (IW-QC2) designed for application by water resource managers and the horticulture industry. This tool is to facilitate decision making on uses of available water resources based on volume and quality needs. IWQC2 model output includes potential rainwater harvesting from greenhouse roofs for user defined greenhouse (plastic and glass) surface areas, water storage and supply capacity for a defined water quality based on crop needs and, the need for desalination treatment. The intent of this tool is to assess water management options and to provide enhanced information to support sustainable growth of the horticulture industry of the NAP region and along the Northern Corridor of South Australia.

\section{METHODOLOGY AND APPROACH}

The area for this study $\left(34^{\circ} 21^{\prime} 48^{\prime \prime}\right.$ to $34^{\circ} 40^{\prime} 24^{\prime \prime} \mathrm{S}$ and $138^{\circ} 25^{\prime} 51^{\prime \prime}$ to $\left.138^{\circ} 54^{\prime} 37^{\prime \prime} \mathrm{E}\right)$ is part of the greater 'Northern Corridor' region, South Australia, Australia. The study area $\left(\sim 825 \mathrm{~km}^{2}\right)$ is located between the Gawler River to the south, Light River to the north, the coast to the west and Thiele Highway to the east that leads to Kapunda in the north as shown in Figure 1. The northern boundary of the NAP-PWA is located within the study area, see Figure 1.

Models were developed for determination of the quantities and qualities of irrigation water from blending of various water resources. E.g. harvested stormwater blended with reclaimed water, used for commonly grown greenhouse crops within the study region. From these models, a software tool in Microsoft Excel) was designed for application by growers for decision-making of storage size and expected water quality of irrigation water. This was performed using continuous simulation models that incorporated historical climate data (between Jan. 
1889 to Jul. 2018) for 42 areas, each $\sim 23.8 \mathrm{~km}^{2}$ within the study area, acquired from the Bureau of Meteorology $(\mathrm{BoM})$ and through the Queensland Government's Scientific Information for Land Owners (SILO) service. A daily time step of precipitation (Pc), Pan A evaporation (Evap.PA) and reference evapotranspiration (ET $\mathrm{E}_{o}$ ) based on the Food and Agriculture Organization Paper 56 (FAO56) short crop, were downloaded for each grid from SILO (State of Queensland, 2019). Median annual Pc, ET ${ }_{o}$ and Evap.pA values at each area were calculated. Median annual Pc values range from $367 \mathrm{~mm}$ to $477 \mathrm{~mm}$ while median annual Evap.PA values range from 1678 $\mathrm{mm}$ to $1850 \mathrm{~mm}$ and median annual $\mathrm{ET}_{o}$ values range from $1275 \mathrm{~mm}$ to $1335 \mathrm{~mm}$.

Charles and Fu (2014) downscaled global circulation models (GCMs) to six better performing GCMs (e.g., GFDL-ESM2M) based on their ability to reproduce drivers of relevance to the South Australian climate. In this research, the median daily values (calculated from the 100 ensembles of the GCM run) from the GFDLESM2M output following an intermediate (RCP4.5) emission scenario (to 2050) at the Edinburg RAAF station was incorporated for this software as an example of climate projections data within the study region. However, application of alternative climate prediction data, could be readily integrated.

The software tool was developed with user selected climate models to provide information (measured as the $10^{\text {th }} \%$ ile, median and $90^{\text {th }} \%$ ile monthly values) on 1) the quantity and quality of irrigation water, 2) outcomes when blending different sources of water, and 3) to predict the quantity of irrigation water and desalination capacity requirements (by Reverse Osmosis-RO, as used in the NAP region) based on the trigger

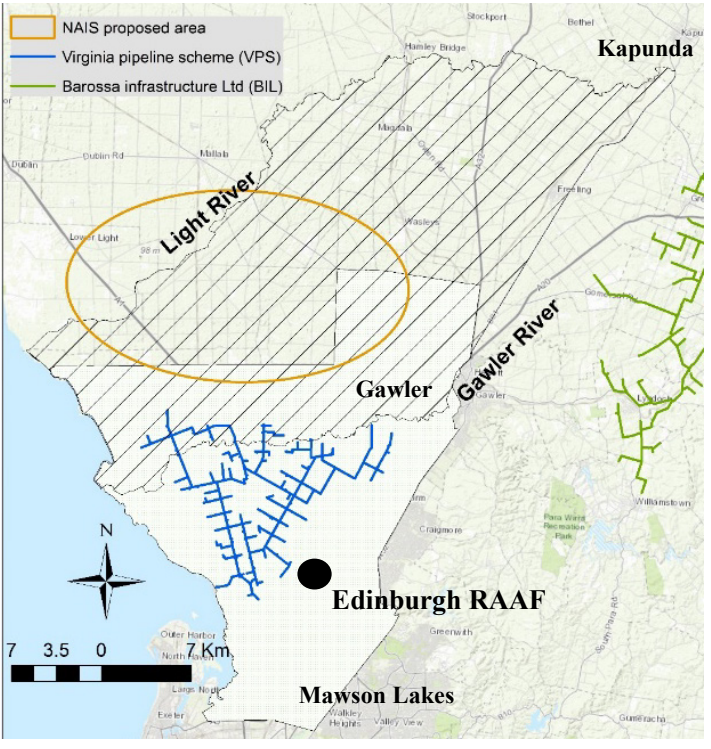

Figure 1. Location of Study area within region of horticultural expansion, in relation to the boundary of groundwater management in the NAP PWA. values for TDS and chloride concentrations.

\subsection{Horticulture practice survey}

To assist in evaluating water source options, an understanding of current irrigation in the NAP region was necessary. The existing horticultural region consists of a broad range of irrigation practices and has wellestablished use of recycled water since 1999. Over this period, the region has also experienced pressures from increased mains water prices, which have impacted on the volume of water produced, and regulated use of limited groundwater resources. A survey was conducted ('face-to-face' questionnaire) of horticulture farmers of the NAP between July and November 2018 (Awad et al., 2019). The questionnaire comprised three categories, seeking information on 1) the crop types grown, 2) irrigation practices applied, and 3) existing water treatment and water storage facilities. Other questions addressed included current practices used to manage soil sodicity and water salinity issues. It was reported that in small enterprises, growers schedule irrigation events based on their past experiences, the growth stage of various crops and the ambient temperature.

\section{MODEL(S) DEVELOPMENT}

Rainwater harvested from greenhouse roofs can be used when captured during the wet season or can be stored and later used to blend with other water sources to achieve target water qualities (i.e., < TDS limits) subsequently during specific growth stages of crop plants (i.e., based on the 2018 survey findings, growers prefer to use a fresher water source during the stages of leaf development and active growth of new shoots of crops). Consequently, two model scenarios were developed, as follows 1) using harvested rainwater when it is available and 2) the harvested rainwater is stored and reused when needed to achieve target water quality (WQ) for supply water. Figure 2 outlines the modelling approach developed.

\subsection{Crop waters}

Models were developed to calculate theoretical irrigation volume needs based on the methodology of Allen et al. (1998). Equations, assumptions and monthly crop coefficient $(\mathrm{kc})$ values used to estimate the crop water 
requirements have been recently reported (Awad et al., 2019). With drip irrigation, only a portion of the soil is wetted and the 'IW-QC2' tool has been adapted to calculate the crop waters based on the wetted soil (equations 1 and 2) as reported by Savva \& Frenken (2002).

$G C=\frac{W_{1} \times \text { No.of plants' lines per house }}{W_{2}} \times 100$
$\mathrm{IR}_{\text {Drip }}=\operatorname{IR} x\left[0.1(G C)^{0.5}\right] x \mathrm{f}_{\text {eff }}$

Where: $G C$ is percentage ground cover; $W_{1}$ is wetted soil width per drip line (estimated to be equal to the distance between the plants: i.e. $0.5 \mathrm{~m}) ; W_{2}$ is the greenhouse width (m); $\mathrm{IR}_{\text {Drip }}$ is the irrigation requirement by drip irrigation system; IR is irrigation requirement; $\mathrm{f}_{\text {eff }}$ is efficiency factors for drip irrigation $(0.95)$ as reported by Savva and Frenken (2002).

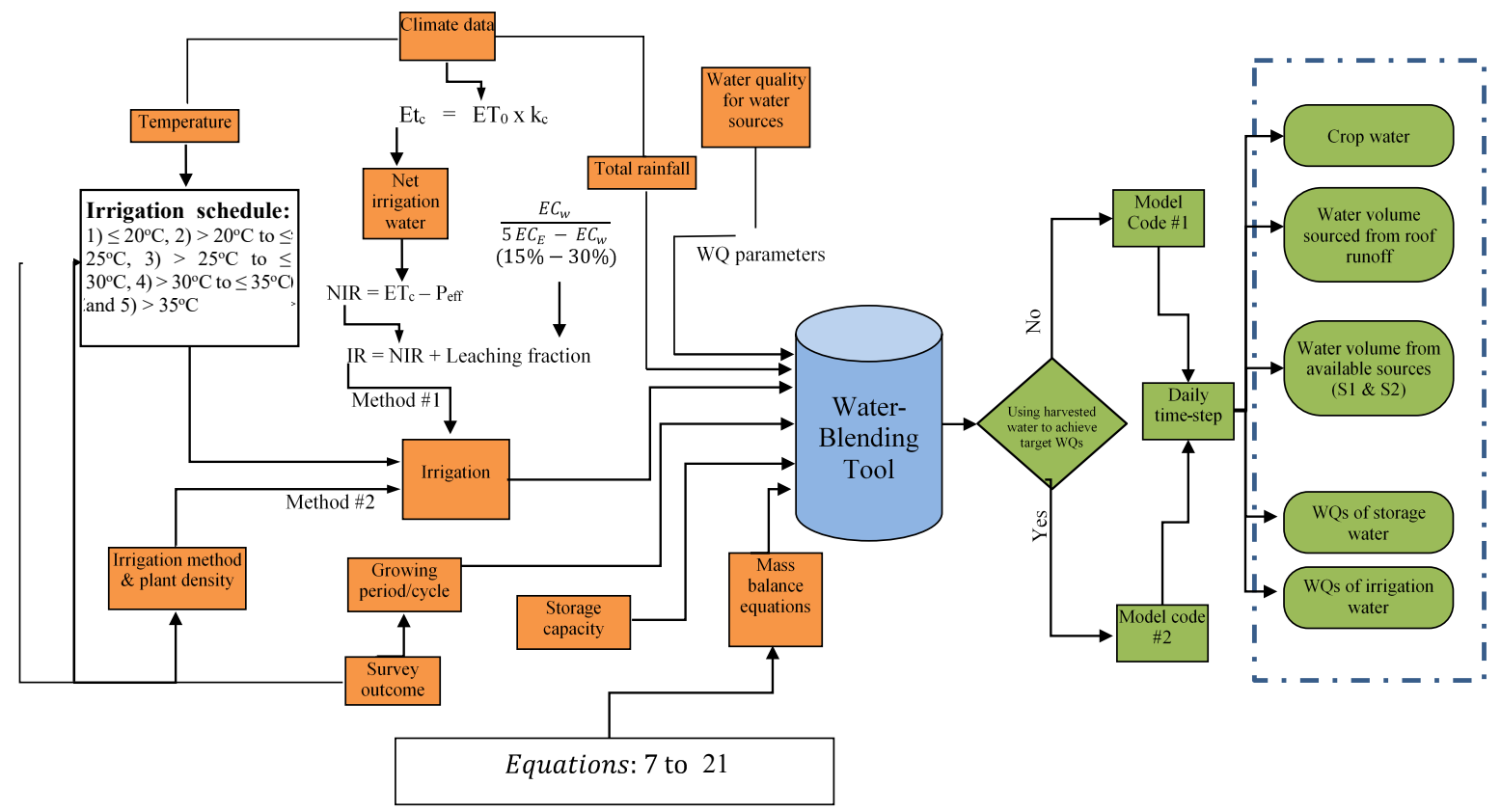

Figure 2. Modelling approach adopted for crop waters and water qualities. Where: $E T_{c}$ is the crop evapotranspiration $(\mathrm{mm}) ; E T_{0}$ is the reference evapotranspiration $(\mathrm{mm}) ; \mathrm{kc}$ is the crop coefficient; $\mathrm{EC}_{\mathrm{w}}$ is salinity of the irrigation water $(\mathrm{dS} / \mathrm{m}) ; E C_{E}$ is salinity tolerance value $(\mathrm{dS} / \mathrm{m}) ; \mathrm{NIR}$ is net irrigation requirement $(\mathrm{mm}) ; \mathrm{P}_{\text {eff }}$ is rainfall effectiveness [0.0 for greenhouse crops]; IR is the irrigation requirement $(\mathrm{mm})$. The tool has been designed to modify the standard $E T_{c}$ to account for specific conditions i.e. without venting (factor $=0.6$ as previously reported e.g., Fernández et al., (2010)).

Growers also opt to use plastic coverings to reduce evaporation losses from the soil and subsequently the tool has been designed to with the option of using a kc value that is reduced by $10 \%$ based on Savva \& Frenken (2002) when a soil plastic covering is used (Equation 3).

$\mathrm{k}_{c_{-} \text {modified }}= \begin{cases}\text { With plastic soil cover } & \mathrm{k}_{c} \times 0.90 \\ \text { Without plastic soil cover } & \mathrm{k}_{c}\end{cases}$

Based on information obtained by the farmer survey, the frequency of irrigation scheduling is dictated by temperature threshold values and these are incorporated into IW-QC2. These temperature ranges are delineated into 5 ranges as follows: 1$\left.) \leq 20^{\circ} \mathrm{C}, 2\right)>20^{\circ} \mathrm{C}$ to $\left.\leq 25^{\circ} \mathrm{C}, 3\right)>25^{\circ} \mathrm{C}$ to $\left.\leq 30^{\circ} \mathrm{C}, 4\right)>30^{\circ} \mathrm{C}$ to $\leq 35^{\circ} \mathrm{C}$ and 5) $>$ $35^{\circ} \mathrm{C}$. The volumes of irrigation water per unit area are also calculated based on actual irrigation practices (including dripper flow rate, number of drippers per greenhouse area) within the region using the following equations (4, 5 and 6$)$ :

No. of drippers per greenhouse $=\frac{\text { No. of plants'lines } \times \text { greenhouse length }}{\text { Drippers sapces }}$

Total No.of Drippers $=\frac{\text { No.of drippers per house } \times \text { total size of the planted area }}{\text { greenhouse width } \times \text { greenhous length }}$

Irrigation volume per event $=$ No. of drippers of total area $x$ dripper flow rate $x$ time of irrigation 


\subsection{Water source volumes and irrigation water qualities}

For the first option "Model Code \#1 objective: use harvested rainwater when it is available", the tool determines the capture of water runoff from roof area $\left(\mathrm{m}^{2}\right)$ and available water storage capacity $\left(\mathrm{m}^{3}\right)$ for immediate use to meet crop demand, as well as other water source(s), if needed. This was done to reduce the required storage size (Eq. 7, to calculate the water volume inside the storage dam at each time step) and subsequently increase the total volume of runoff that could be captured (Eq. 8, to estimate the total harvested rainwater).

$$
\begin{aligned}
& D S_{\max } \quad \text { at: }\left(D S_{t-1}+Q_{\text {Runoff }_{t}}-Q_{\text {Evap }_{t}}-Q_{\text {Irr }_{t}}\right)>D S_{\max } \\
& D S_{t}=\left\{\begin{array}{cl}
D S_{\text {min }} & \text { at: }\left(D S_{t-1}+Q_{\text {Runoff }_{t}}-Q_{\text {Evap }_{t}}-Q_{\text {Irr }}\right)<D S_{\text {min }} \\
D S_{t-1}+Q_{\text {Runof }_{t}}-Q_{\text {Evap }_{t}}-Q_{\text {Irr }} & \text { at: } D S_{\text {min }}<\left(D S_{t-1}+Q_{\text {Runoff }_{t}}-Q_{\text {Evap }_{t}}-Q_{\text {Irr }}\right) \leq D S_{\text {max }}
\end{array}\right. \\
& Q_{\text {Runoff }_{t}}= \begin{cases}Q_{\text {TRunoff }_{t}} & \text { at: }\left(D S_{t-1}+Q_{\text {TRunoff }_{t}}-Q_{\text {Evap }_{t}}-Q_{\text {Irr }_{t}}\right) \leq D S_{\text {max }} \\
D S_{\text {max }}-D S_{t-1}+Q_{\text {Evap }_{t}}+Q_{\text {Irr }_{t}} & \text { at: }\left(D S_{t-1}+Q_{\text {TRunoff }_{t}}-Q_{\text {Evap }_{t}}-Q_{\text {Irr }}\right)>D S_{\text {max }}\end{cases}
\end{aligned}
$$

Where: $\mathrm{t}$ is the time $(\mathrm{d}) ; D S_{t}$ is the water volume $\left(\mathrm{m}^{3}\right)$ inside the storage dam at time $(\mathrm{t}) ; D S_{\max }$ is total capacity of the storage facility $\left(\mathrm{m}^{3}\right) ; D S_{\min }$ is minimum storage volume that required to be detained on the storage facility $\left(\mathrm{m}^{3}\right) ; D S_{t-1}$ is the water volume $\left(\mathrm{m}^{3}\right)$ inside the storage dam at time $(\mathrm{t}-1) ; Q_{\text {Runof } f_{t}}$ is the actual harvested rainwater from the greenhouses' roof $\left(\mathrm{m}^{3}\right)$ at time $(\mathrm{t}) ; Q_{\text {Evap }}$ is the evaporated water volume from the storage facility $\left(\mathrm{m}^{3}\right)$ at time $(\mathrm{t}) ; Q_{\text {Irr }}$ is the total irrigation volume $\left(\mathrm{m}^{3}\right)$ at time $(\mathrm{t}) ; Q_{\text {TRunof } f_{t}}$ is the total rainwater that could be harvested from greenhouse roofs $\left(\mathrm{m}^{3}\right)$ at time $(\mathrm{t})$.

For Model Code \#1, the following mass balance equations (Eqs. 9 to 11) are used to estimate the volume of water source(s) for each irrigation event. Eq. 9 was used to estimate the required water volume from sources (source \#1: S1 or source\#2: S2) other than harvested rainwater. This volume will be from S1 (Eq. 10) for the following conditions: 1) TDS of S1 is lower than TDS of S2 and the required volume from S1 is available at this time step, or 2) TDS of S1 is higher than TDS of S2 but the required volume from S2 is not available at this time step. From Eq. $9 \& 10$, the required water volume from S2 (Eq. 11) can be estimated.

$$
\begin{aligned}
& Q_{S_{t}}=D S_{t}-D S_{t-1}+Q_{\text {Irr }_{t}}+Q_{\text {Evap }_{t}}-Q_{\text {Runoff }} \\
& Q_{S 1_{t}}= \begin{cases}Q_{S_{t}} & \text { at } \begin{cases}T D S_{S 1_{t}}<T D S_{S 2_{t}} \text { and } & Q_{S 1_{M_{-} L}}<\sum_{i=1}^{t} Q_{S 1_{i}} \\
T D S_{S 1_{t}}>T D S_{S 2_{t}} \text { and } & Q_{S 2_{M_{-} L}}>\sum_{i=1}^{t} Q_{S 2_{i}}\end{cases} \\
0.0 & \text { at }\left\{\begin{array}{lll}
T D S_{S 1_{t}}<T D S_{S 2_{t}} \text { and } & Q_{S 1_{M_{-} L}}>\sum_{i=1}^{t} Q_{S 1_{i}} \\
T D S_{S 1_{t}}>T D S_{S 2_{t}} \text { and } & Q_{S 2_{M_{-} L}}<\sum_{i=1}^{t} Q_{S 2_{i}}
\end{array}\right.\end{cases} \\
& Q_{S 2_{t}}=Q_{S_{t}}-Q_{S 1_{t}}
\end{aligned}
$$

Where: $Q_{S_{t}}$ is the required water volume $\left(\mathrm{m}^{3}\right)$ from other sources at time $(\mathrm{t}) ; Q_{S 1_{t}}$ is the required water volume $\left(\mathrm{m}^{3}\right)$ from $\mathrm{S} 1$ at time $(\mathrm{t}) ; Q_{S 2_{t}}$ is the required water volume $\left(\mathrm{m}^{3}\right)$ from $\mathrm{S} 2$ at time $(\mathrm{t}) ; Q_{S 1_{M_{-} L}}$.is the monthly licensed volume of $\mathrm{S} 1\left(\mathrm{~m}^{3}\right) ; Q_{S 2_{M_{-} L}}$. is the monthly licensed volume of $\mathrm{S} 2\left(\mathrm{~m}^{3}\right) ; \sum_{i=1}^{t} Q_{S 1_{i}}$ is the total monthly volume $\left(\mathrm{m}^{3}\right)$ used from $\mathrm{S} 1$ up to this time step $(\mathrm{t}) ; \sum_{i=1}^{t} Q_{S 2_{i}}$ is the total monthly volume $\left(\mathrm{m}^{3}\right)$ used from $\mathrm{S} 2$ up to this time step $(\mathrm{t})$.

Various WQs (i.e. $\mathrm{pH}$, TDS, chloride, $\mathrm{Na}, \mathrm{Mg}, \mathrm{Ca}, \mathrm{P}$ ) of irrigation water are calculated based on the following equation (Eq. 12):

$W Q_{D S_{t}}=\frac{W Q_{S 1_{t}} \times Q_{S 1_{t}}+W Q_{S 2_{t}} \times Q_{S 2_{t}}+W Q_{D S_{t-1}} \times Q_{E v a p_{t}}+W Q_{R u n o f f} \times Q_{R u n o f f_{t}}+W Q_{D S_{t-1}} \times D S_{t-1}}{Q_{S 1_{t}}+Q_{S 2_{t}}+Q_{E v a p_{t}}+Q_{R u n o f f}+D S_{t-1}}$

Where: $W Q_{D S_{t}}$ is the water quality parameter of storage dam water, at time (t); $W Q_{S 1_{t}}$ is the corresponding WQ of water from source $1(\mathrm{~S} 1)$ at time $(\mathrm{t}) ; W Q_{S 2_{t}}$ is the corresponding WQ of water from source $2(\mathrm{~S} 2)$ at time $(\mathrm{t}) ; W Q_{D S_{t-1}}$ is the corresponding WQ of water inside the storage dam at time (t-1); $W Q_{\text {Runoff }}$ is the corresponding WQ of water from roof runoff at time ( $\mathrm{t}$ ).

For the second option "Model Code \#2: using harvested and stored water to achieve target TDS", the tool has been designed to calculate the maximum volume of roof runoff water that could be captured, based on the roof area $\left(\mathrm{m}^{2}\right)$ and climate data. Harvested rainwater is stored and then blended with other water source(s) to achieve the required monthly TDS values if applicable, equations (13:21). Eq. 13 is used to identify water source other than harvested rainwater (between S1 and S2), based on the TDS value and the availability of waters. Consequently, the TDS at this time step (Eq. 14) is selected. 


$$
\begin{aligned}
& Q_{S_{t}} \text { source }= \begin{cases}S 1_{t} & \text { at } \begin{cases}T D S_{S 1_{t}}<T D S_{S 2_{t}} \text { and } & Q_{S 1_{M_{-} L}}<\sum_{i=1}^{t} Q_{S 1_{i}} \\
T D S_{S 1_{t}}>T D S_{S 2_{t}} \text { and } & Q_{S 2_{M_{-} L}}>\sum_{i=1}^{t} Q_{S 2_{i}}\end{cases} \\
S 2_{t} & \text { at } \begin{cases}T D S_{S 1_{t}}<T D S_{S 2_{t}} \text { and } Q_{S 1_{M_{-} L}}>\sum_{i=1}^{t} Q_{S 1_{i}} \\
T D S_{S 1_{t}}>T D S_{S 2_{t}} \text { and } Q_{S 2_{M_{-} L}}<\sum_{i=1}^{t} Q_{S 2_{i}}\end{cases} \end{cases} \\
& T D S s_{t}= \begin{cases}T D S_{S 1_{t}} & \text { at: } Q_{S_{t}} \text { source }=S 1_{t} \\
T D S_{S 2_{t}} & \text { at: } Q_{S_{t}} \text { source }=S 2_{t}\end{cases}
\end{aligned}
$$

From Eqs 13 \& 14, and target TDS value (TDS target $_{\text {) }}$, the initial water volume from the other source (Eq. 15) and required harvested rainwater volume $\left(Q_{\text {Runoff }_{-} 1_{t}}\right.$, Eq. 16) to achieve the target TDS are estimated.

$Q_{S_{t}}=\frac{Q_{\text {Irr }} \times T D S_{\text {Target }_{t}}-Q_{\text {Irr }} \times T D S_{\text {Runoff }_{t}}}{T D S_{S_{t}}-T D S_{\text {Runoff }_{t}}}$

$Q_{\text {Runoff } 1_{t}}=Q_{\text {Irr }}-Q_{S_{t}}$

The maximum storage capacity $\left(\mathrm{DS}_{\max }\right.$ ) has been estimated as $300 \mathrm{~m}^{3}$ per hectare of greenhouse roof while the minimum storage volume ( $\mathrm{DS}_{\min }$ ) that is required to be detained on the storage facility has been estimated to be $20 \%$ of the storage capacity. From Eq. 16, the initial storage capacity (Eq. 17) is estimated based on the total harvested runoff that can be captured at this time step $\left(Q_{T R u n o f f_{t}}\right), \mathrm{DS}_{\max }$ and $\mathrm{DS}_{\min }$ values. This is used to adjust the volume of harvested rainwater volume $\left(Q_{\text {Runoff }_{-} 2_{t}}\right)$ that could be captured (Eq. 18).

$$
\begin{aligned}
& D S_{\text {Runoff } 1_{-} 1_{t}}=
\end{aligned}
$$

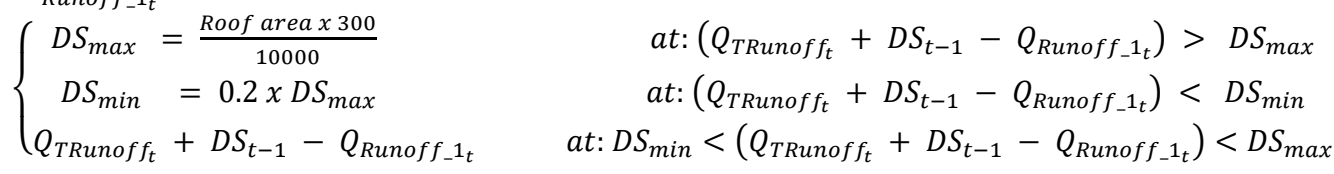

$$
\begin{aligned}
& Q_{\text {Runoff_2 }}{ }_{t}=
\end{aligned}
$$

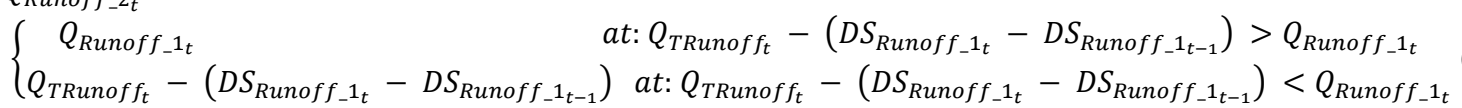

A conditional function (Eq. 19) is used to re-estimate the storage capacity $\left(D S_{\max }\right)$ and consequently recalculate the harvested rainwater based on the ratio between the adjusted and initial volumes of harvested rainwater.

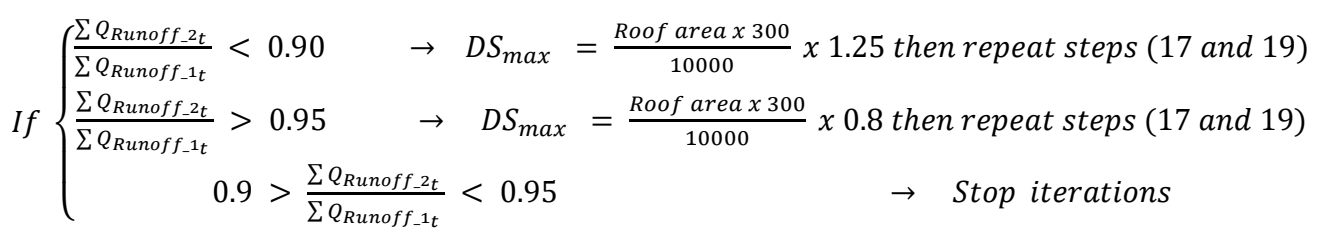

The iterations stop once the calculated ratio (the adjusted to initial volumes of harvested rainwater) reaches the thresholds values (between 0.9 and 0.95 ). Using the final value of harvested rainwater, the required water volume from other sources (Eq. 20 for S1 and Eq. 21 for S2) is recalculated.

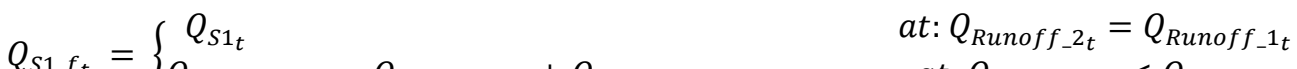

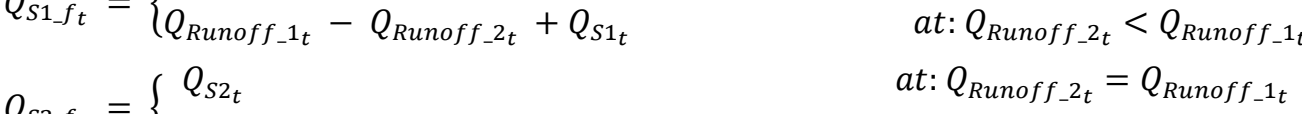

$$
\begin{aligned}
& Q_{S 2_{-} f_{t}}= \begin{cases}Q_{S 2_{t}} & \text { at: } Q_{\text {Runoff } 2_{t}}=Q_{\text {Runoff }} 1_{t} \\
Q_{\text {Runoff } 1_{-} 1_{t}}-Q_{\text {Runoff } 2_{-}}+Q_{S 2_{t}} & \text { at: } Q_{\text {Runoff } 2_{-} t_{t}}<Q_{\text {Runoff }} 1_{-} 1_{t}\end{cases}
\end{aligned}
$$

From Eqs. 18, $20 \& 21$, actual WQs of irrigation water are calculated (Eq. 12).

\section{EXAMPLE OF APPLICATION OF THE TOOL}

In order to examine the effect of storage capacity on the potential volume of rainwater that could be harvested and WQ of irrigation water, the tool was applied to a greenhouse planted with capsicum under the following dam storage volumes: 0.0 (no rainwater harvesting), 50, 100, 150, 200,300, 500 and $1000 \mathrm{~m}^{3}$. A power function was used to describe the relation between dam storage volume and potential volume of rainwater that could be harvested from the greenhouse runoff. An exponential decay function was used to identify the relation between dam storage volume and annual salt load. A recommended storage volume $\left(300 \mathrm{~m}^{3}\right)$ was calculated based on salt load, where storage volume resulted in the required capture amount of roof runoff that leads to reduction of salt load by at least $50 \%$ of the maximum potential reduction of salt load. This indicates that a small on-site storage can compensate for the potential reduction in volume of harvested runoff under a future climate. 
Compared with historical climate data (at Edinburg RAAF weather station, SA), the climate change projections model (median values of the GFDL-ESM2M model, based on projection to 2050) was found to reduce the potential volume of rainwater that could be harvested per annum by $\sim 12 \%$ and increase the amount of water that would be required from another source (e.g. reclaimed water) by $\sim 26 \%$. Consequently, the salt load added to the system could potentially increase by $\sim 25 \%$ per annum.

\section{CONCLUSION}

Models and a software tool (IW-QC2) were developed for application with user selected climate models for determination of 1) the quantities and qualities of irrigation water, 2) volumes of water that could be harvested from impervious greenhouse roofs and storage requirements, 3) outcomes when blending different sources of water such as harvested stormwater with other sources, and 4) to predict the quantity of irrigation water and desalination requirements (by RO, as used in the NAP region) based on the trigger values for TDS and chloride concentrations. The Excel-based tool, tailored to horticulture in the NAP region, was developed for use by water resource managers and the horticulture industry to facilitate decision-making on water resource selection, the required water storage capacity and the quality the blended water supply available for use in irrigation. This tool is intended to support economic growth through expansion of the horticultural industry in the Northern Adelaide Corridor region of South Australia.

\section{ACKNOWLEDGMENTS}

The authors gratefully acknowledge the financial support provided by the Goyder Institute for Water Research for this work under the project (Project Number ED-17-01)." We thank the growers of the NAP who participated in the farmer survey conducted, Mr Paul Pezzaniti, Dr Jim Cox and other project colleagues for their support in this study.

\section{REFERENCES}

Allen, R. G., L. S. Pereira, D. Raes and M. Smith (1998). Crop evapotranspiration-Guidelines for computing crop water requirements-FAO Irrigation and drainage paper 56. Fao, Rome 300(9), D05109.

Awad, J., J. Vanderzalm, D. Pezzaniti, O.-O. Esu and J. van Leeuwen (2019). Sustainable Expansion of Irrigated Agriculture and Horticulture in Northern Adelaide Corridor: Source water options/water availability, quality and storage consideration. Goyder Institute for Water Research Technical Report No 19/16, Adelaide, South Australia.

Charles, S. and G. Fu (2014). Statistically Downscaled Projections for South Australia-Task 3 CSIRO Final Report. Goyder Institute for Water Research, Technical Report Series(15/1).

Fernandes, C., J. E. Corá, J. A. C. D. Araújo (2003). Reference evapotranspiration estimation inside greenhouses. Scientia Agricola, 60, 591-594.

Jaramillo, M. and I. Restrepo (2017). Wastewater reuse in agriculture: A review about its limitations and benefits. Sustainability $9(10), 1734$.

Kelly, J., M. van der Wielen and D. Stevens (2001). Sustainable use of recliamed water on the Northern Adelaide Plains: Grower Mannual.

PIRSA (2017). Northern Adelaide Irrigation Scheme (NAIS). https://www.pir.sa.gov.au/major programs /northern_adelaide plains_agribusiness_initiative/northern adelaide_irrigation_scheme, accessed 21/6/2019

Reca, J., C. Trillo, J. A. Sánchez, J. Martínez and D. Valera (2018). Optimization model for on-farm irrigation management of Mediterranean greenhouse crops using desalinated and saline water from different sources. Agricultural Systems 166, 173-183.

Resh, H.M. (2012). Hydroponic food production: a definitive guidebook for the advanced home gardener and the commercial hydroponic grower and the commercial hydroponic grower.

Stevens, D. P., M. J. McLaughlin and M. K. Smart (2003). Effects of long-term irrigation with reclaimed water on soils of the Northern Adelaide Plains, South Australia. A. Journal of Soil Research 41(5), 933948

Savva, A. P. and K. Frenken (2002). Irrigation manual: planning, development monitoring and evaluation of irrigated agriculture with farmer participation.

State of Queensland (Queensland Department of Environment and Science) (2019). SILO climate database, Queensland Government, https://silo.longpaddock.qld.gov.au/gridded-data) 